\title{
Letter from the Invited Editor, Special Issue on DEA and MCDA
}

If we turn back to the origins of Operations Research, we will promptly recognize its major mission: to help Britain and USA in defeating fascism during the Second World War. Nowadays, OR's mission is not so distinguishable, even though we face challenges comparable to a war, like food scarcity, health service deficiencies, lack of education and provision for other basic needs, corruption, urban violence, drug traffic and so on. At first glance, OR is much more appropriate for industrial applications than for social and public matters. This is probably due to the complex and multidisciplinary nature of the latter, but these are still characteristics of the real world, and we should always remember that one of the main barriers to OR success (given its quantitative nature) is an inaccurate adherence to real world problems.

DEA and MCDA certainly fit into the category of OR tools that deal with complex multidisciplinary subjects. DEA was conceived as a method of performance assessment in the public sector, where the "invisible hand" of the market could not touch in order to select the "most efficient" firms or programs.

At this very moment, Brazil is experiencing political changes that can result in further nationwide transformations. Brazilians will have a great opportunity to concentrate all their efforts to reduce restrictions to social and economic development, and this includes integration between scientific research and problem solving. DEA and MCDA have their share of responsibility to the extent that they can help in providing a systematized comprehensive environment where democratic decisions could be made, taking into account a fair performance judgement.

In this sense, the special issue of Pesquisa Operacional devoted to DEA and MCDA intend to stimulate theoretical research aiming at adequately solving real world problems, faithfully pursuing the original meaning of putting together the words Operational and Research.

We wish to acknowledge Professors Horacio Hideki Yanasse and Luis Flávio Autran Monteiro Gomes for their incentive that made this issue possible, also Prof. Charles Albert Knox Lovell and all the referees who worked so hard in order to improve the standard of the submitted articles.

Marcos P. Estellita Lins, PEP - UFRJ 